\title{
Prevalence and Factors associated with Hearing Impairment in Preschool Children in Albania
}

\author{
Suela Sallavaci* \\ University Hospital Center "Mother Teresa", Tirana, Albania
}

*Corresponding author: Suela Sallavaci, University Hospital Center "Mother Teresa", Tirana, Albania, Tel: 355692073349 ; E-mail: mailto:sallavacis@hotmail.com

Rec date: Jun 25, 2016; Acc date: Jul 01, 2016; Pub date: Jul 08, 2016

Copyright: (C) 2016 Sallavaci S. This is an open-access article distributed under the terms of the Creative Commons Attribution License, which permits unrestricted use, distribution, and reproduction in any medium, provided the original author and source are credited.

Citation: Sallavaci S. Prevalence and Factors Associated with Hearing Impairment in Preschool Children in Albania. Arch Med. 2016, 8:4

\section{Abstract}

Background: Hearing impairment $(\mathrm{HI})$, a condition that affects disproportionally children in developing countries, could negatively impact the development of communications skills of involved children when not timely detected and treated.

Aims: We aimed to assess the prevalence of $\mathrm{HI}$ and the factors and health conditions associated with it, among preschool children in Albania.

Study design: Cross-sectional survey.

Methods: During November 2009-May 2011 a simple random sample of 400 preschool children aged 4-6 years old and attending public kindergartens in urban and rural areas of Tirana, the capital of Albania were examined about hearing ability via tonal audiometry and tympanometry. $\mathrm{HI}$ was defined by a threshold of $\geq 20 \mathrm{~dB}$ in the better ear. In addition, objective examination of ear, nose and pharynx was carried out in order to detect potential structures and/or diseases contributing to $\mathrm{HI}$. Binary logistic regression was used to assess the factors associated with $\mathrm{HI}$ in this sample of preschool children.

Results: In this sample of children (51\% females, $73.5 \%$ urban residence) the total prevalence of $\mathrm{HI}$ was $16 \%$. Otitis Media with effusion, suppurative otitis media and past otitis media was present in $14.6 \%, 1 \%$ and $13.1 \%$ of cases, respectively. Upon adjustment for several confounding effects, the only factors significantly associated with $\mathrm{HI}$ were current otitis media in objective examination (OR=5.62; $95 \% \mathrm{Cl}: 2.18-14.4)$ and recurrent otitis media in anamnesis (OR=1.82; $95 \% \mathrm{Cl}$ : 1.33-2.51).

Conclusions: $\mathrm{HI}$ is a common and serious condition that might negatively affects the future development of preschool children. Routine screening of newborn and/or preschool children is an effective way to address this problem in Albania.

Keywords: Hearing impairment; Preschool children; Screening; Otitis media

\section{Introduction}

Hearing Impairment (or Hearing Loss), which includes conductive or sensorineural hearing loss or a mixture of the two involving single or both ears, is of critical importance when diagnosed in children because it might negatively affect the future development of speech, language and communications skills as well as their academic performance [1-3]. Furthermore, hearing impairment can put children at higher risk of physical, social and emotional abuse and later during adulthood it can be associated with feeling embarrassed, loneliness, social isolation, abuse, depression, uneasy relationships, low career opportunities and low earnings [4].

According to the World Health Organization, there were approximately 360 million people living with disabling hearing loss in 2011, around 32 million of whom were children under 15 years of age [2]. Among the later, 7.5 million were children aged less than 5 years [4]. Disabling hearing loss in children younger than 15 years old is defined as hearing loss $\geq 31 \mathrm{~dB}$ in the better hearing ear [2]. According to the World Health Organization (WHO), there is an exponential negative relationship between gross national income (GNI) and prevalence of hearing loss in children age $<15$ years with the prevalence of hearing loss peaking up to almost $3 \%$ in very low GNI countries compared to as low as $0.5 \%$ in high income countries [2]. Disabling hearing loss in children younger than 15 years is also negatively associated with the average level of adult literacy [2].

The prevalence of disabling hearing loss among children younger than 15 years in Central/Eastern Europe was 1.6\% in 2011, ranging from $0.5 \%$ in high income countries to $2.4 \%$ in South Asia, with a world average prevalence of $1.7 \%$ (3). In USA, up to 3 in every 1,000 children are born with some level of hearing loss in one or both ears [5].

Early detection of hearing impairment [in preschool children] and subsequent corrective measures can improve school attainment and communication skills [6]. In this context, screening of preschool children for early detection of hearing impairment is now mostly routine in developed countries [6]. In developing countries, characterized by limited 
resources (both financially and in terms of equipment and expertise) and priority settings, often such exercise does not get the necessary attention even though the burden of hearing impairment might be considerable [6].

In young children, the factors which increase the risk of hearing loss might include some infectious diseases such as Measles, Mumps and Meningitis, as well as chronic otitis media $[2,3]$. More than $80 \%$ of children will experience at least one episode of acute otitis media before the age of 3 years and, after onset of otitis media, middle ear effusion usually persist for weeks to months [7]. Furthermore, the onset of otitis media earlier in life increases the risk of recurrent infections later in life [7]. Also, maternal infections [such as Rubella], severe jaundice following birth, birth anoxia, ototoxic drugs, low birth weight and loud noise could increase the risk of impaired hearing and deafness as well [2].

In Albania, a small country in South East Europe, there is no information on the number of hearing loss cases attributed to measles or mumps, but supposedly this should be extremely low (almost zero) since almost all children (approximately 98\%) are covered by the National Immunization Program [8]. In addition, there is no information on the prevalence and factors associated with hearing loss among young children aged 4-6 years old.

In this context the aim of this paper was to assess the prevalence of hearing loss as well as factors and health conditions associated with it among preschool children in Tirana, Albania.

\section{Material and Methods}

\section{Study population and sampling}

The target population comprised of all children aged 4-6 years old frequenting public kindergartens in Tirana district, the capital of Albania. Almost one third of Albania's total population resides in Tirana, due to the massive migration process, a phenomenon occurring on a large scale since the collapse of the communist regime in 1991 and affecting the major Albanian cities. Because of this process, the Tirana population represents a mixture of all people coming from all parts of the country.

Tirana district has around 40 public kindergartens (sampling frame), even though there is need for several times more. As a result, more than $65 \%$ of preschool children are not able to access public kindergartens due to the limited number of the later [9]. The list of all children aged 4-6 years old enrolled in public kindergartens was retrieved from the Ministry of Education and to each of them was assigned a unique code. Because the data collection process lasted for about 18 months, then obviously some children from the original sampling frame would get out of it because of growing up and moving to the school system. However, his/her place was replaced by another child and therefore this did not impact the way of selection.
The sample size was calculated using conservative assumptions. The level of statistical significance was set at $5 \%$ and the power of the study at $80 \%$. The statistical software WinPepi was used for the computation of the sample size, resulting in $\mathbf{3 7 5}$ children. In order to increase the study power, we decided to examine 400 children. STATA statistical package was used to generate a random sample of children based on the given sample size and stratified by kindergartens.

\section{Data collection}

The data collection process took place from November 2009 to May 2011. Data collection consisted in hearing test and clinical examination of selected children as well as retrieving information about their basic socio-demographic characteristics.

Audiology examinations were carried out using a AA222 audiotympanometer; in order for getting more detailed data we performed $125-8000 \mathrm{~Hz}$ tonal audiometry and tympanometry.

Since the ear is anatomically adjacent to other organs and knowing that diseases of these organs could affect hearing, clinical examination of nose, throat and pharynx were performed in addition to ear examination. The clinical examination of children aimed to detect any potential health condition associated with hearing loss such as presence of nasal hypertrophy and adenoids, tonsillar hypertrophy of various degrees and otitis media. We used anterior rhinoscopy for examining the nose and detecting the presence of nasal hypertrophy; conversely, posterior rhinoscopy was used to detect adenoids. The mouth was also examined to detect diseases affecting tonsils and the pharynx. Ear examination and otoscopy were performed for detecting any potential disease of external auditory canal, the state of tympanic membrane and potential diseases of middle ear. Children's mothers were asked to kindly provide information about episodes of otitis media, rhinopharyngitits and antibiotic use during the last three years.

Information about sex of the participating children was recorded. In addition, we retrieved information about children's place of residence (urban vs. rural) and mother's education level.

The study was approved by the Committee of Bio-Medical Ethics of Albania.

\section{Statistical analysis}

When detected, Hearing Loss was categorized as follows: normal (-10 to $19 \mathrm{~dB}$ ); slight/mild (20-30 dB); and moderate/ severe hearing loss (>30 dB). Tonsillar hypertrophy was categorized into normal, first grade, second and third grade. Presence of otitis media was categorized into normal tympanic membranes, otitis media with effusion and purulent otitis. Dichotomous variables included adenoids, antibiotic use, sex and place of residence. Mother's education level was defined as primary/secondary, high school and university education. 
Absolute numbers and respective percentages were calculated and reported. To detect differences in proportions across categorical variables the chi square test was performed. The 95\% confidence interval $(\mathrm{Cl})$ for different proportions was calculated and reported. Binary logistic regression was used to detect the factors associated with Hearing loss in this sample of preschool children, reporting odds ratios (OR). In all cases an association was regarded as statistically significant if the $p$ value $\leq 0.05$. All the statistical analysis was performed using STATA statistical package, version 9.0.

\section{Results}

A total of 400 preschool children ( $49 \%$ males) aged 4-6 years old participated in the survey. Around three-quarters of participants resided in urban areas (Table 1). In 33.7\% and $48.3 \%$ of cases the respective mothers had secondary or high school education level (Table 1).
The prevalence of adenoids, tonsillar hypertrophy, current otitis media, past otitis media and past Rhinopharyngitis was $31.2 \%, 53.3 \%, 15.6 \%, 24.1 \%$, and $13.1 \%$, respectively, in this sample of children (Table 1).

The prevalence of recurrent rhinophayrngitis and recurrent otitis media was $19.1 \%$ and $8.3 \%$, respectively, whereas past antibiotic use was reported in $63.1 \%$ of cases.

The prevalence of slight to mild hearing loss was $15.5 \%$ whereas the prevalence of moderate-to-severe hearing loss was $0.5 \%$ (Table 1 ).

Table 1 General characteristics of the study population.

\begin{tabular}{|c|c|c|c|}
\hline Variable & Absolute number & Percentage & $95 \% \mathrm{Cl}$ \\
\hline \multicolumn{4}{|l|}{ Sex } \\
\hline Male & 196 & 49 & $44.0 \%-54.0 \% \ddagger$ \\
\hline Female & 204 & 51 & $46.0 \%-56.0 \%$ \\
\hline \multicolumn{4}{|l|}{ Place or residence } \\
\hline Urban & 294 & 73.5 & $68.9 \%-77.8 \%$ \\
\hline Rural & 106 & 26.5 & $22.4 \%-31.1 \%$ \\
\hline \multicolumn{4}{|l|}{ Mother's education level } \\
\hline Primary/secondary & 135 & 33.7 & $29.1 \%-38.6 \%$ \\
\hline High school & 193 & 48.3 & $43.3 \%-53.3 \%$ \\
\hline University & 72 & 18 & $14.4 \%-22.1 \%$ \\
\hline \multicolumn{4}{|l|}{ Adenoids* } \\
\hline Present & 124 & 31.2 & $26.6 \%-36.0 \%$ \\
\hline Not present & 274 & 68.8 & $64.0 \%-73.4 \%$ \\
\hline \multicolumn{4}{|l|}{ Tonsillar hypertrophy* } \\
\hline Not present (normal) & 186 & 46.7 & $41.8 \%-51.8 \%$ \\
\hline 1st grade & 124 & 31.2 & $26.6 \%-36.0 \%$ \\
\hline 2nd grade & 70 & 17.6 & $14.0 \%-21.7 \%$ \\
\hline 3rd grade & 18 & 4.5 & $2.7 \%-7.9 \%$ \\
\hline \multicolumn{4}{|l|}{ Current Otitis Media* } \\
\hline Normal tympanic membrane & 336 & 84.4 & $80.5 \%-87.8 \%$ \\
\hline Otitis media with Effusion & 58 & 14.6 & $11.3 \%-18.4 \%$ \\
\hline Purulent otitis media & 4 & 1 & $0.3 \%-2.6 \%$ \\
\hline \multicolumn{4}{|c|}{ Past Otitis Media or Rhinopharyngitis * } \\
\hline Never had & 250 & 62.8 & $58.6 \%-66.8 \%$ \\
\hline
\end{tabular}




\begin{tabular}{|c|c|c|c|}
\hline Rhinopharyngitis & 96 & 24.1 & $20.0 \%-28.6 \%$ \\
\hline Otitis media & 52 & 13.1 & $9.9 \%-16.8 \%$ \\
\hline \multicolumn{4}{|c|}{ Recurrent Otitis Media or Rhinopharyngitis $†$} \\
\hline Recurrent Rhinopharyngitis & 76 & $19.1 \dagger$ & $15.9 \%-23.3 \%$ \\
\hline Recurrent otitis media & 33 & 8.3 & $5.8 \%-11.5 \%$ \\
\hline \multicolumn{4}{|l|}{ Past antibiotic use } \\
\hline Yes & 236 & 63.1 & $58.0 \%-68.0 \%$ \\
\hline No & 138 & 36.9 & $32.0 \%-42.0 \%$ \\
\hline \multicolumn{4}{|l|}{ Hearing impairment level } \\
\hline Normal audiogram & 336 & 84 & $80.0 \%-87.5 \%$ \\
\hline Slight-mild & 62 & 15.5 & $12.1 \%-19.4 \%$ \\
\hline Moderate-severe & 2 & 0.5 & $0.1 \%-1.8 \%$ \\
\hline $\begin{array}{l}\text { *Discrepancies with the total } \\
\text { †Proportion within } 398 \text { subje } \\
{ }^{\star} 95 \% \text { confidence interval (Cl }\end{array}$ & & & \\
\hline
\end{tabular}

In univariate analysis, hearing loss was not statistically different by gender and presence of adenoids (Table 2). Conversely, hearing loss was statistically more prevalent among rural children and children whose mothers had low education level ( $p=0.013$ and $p=0.024$, respectively) (Table 2). Apparently, the presence of abnormal structures in pharynx or infections of ear is associated with significantly higher prevalence of hearing loss.

Here it is necessary to highlight the fact that the association with tonsillar hypertrophy grade does not follow any clear trend. When the significance test is computed by omitting the "normal" category, the association of hearing loss with tonsillar hypertrophy grade turn not significant $(p=0.091$, data not shown). The association with otitis media is clear with the prevalence of hearing loss significantly increasing when moving from intact tympanic membrane (10.4\%) to otitis media with effusion (43.1\%) and to purulent otitis media $(50.0 \%)(p<0.001)$ (Table 2).

Similarly, past and recurrent rhinopharyngitis or otitis media is associated with significantly higher prevalence of hearing loss in this sample of preschool children $(p<0.05)$. Finally, use of antibiotics in the past, indicating past infections of ear, is associated with significantly higher prevalence of hearing loss compared to no history of antibiotic use $(25.4 \%$ vs. $13.8 \%$, respectively, $p=0.008$ ).

Table 2 Distribution of hearing impairment by socio-demographic characteristics of participants and various health conditions.

\begin{tabular}{|c|c|c|c|}
\hline \multirow{2}{*}{ Variable } & \multicolumn{2}{|c|}{ Status of hearing impairment } & \multirow{2}{*}{ p-value } \\
\hline & No hearing impairment & Hearing impairment $†$ & \\
\hline \multicolumn{4}{|l|}{ Sex } \\
\hline Male & $168(85.3)^{*}$ & $29(14.7)$ & $0.492 \ddagger$ \\
\hline Female & $168(82.8)$ & $35(17.2)$ & \\
\hline \multicolumn{4}{|l|}{ Place or residence } \\
\hline Urban & $255(86.7)$ & $39(13.3)$ & 0.013 \\
\hline Rural & $81(76.4)$ & $25(23.6)$ & \\
\hline \multicolumn{4}{|c|}{ Mother's education level } \\
\hline Primary/secondary & $106(78.5)$ & $29(21.5)$ & 0.024 \\
\hline High school & $163(84.5)$ & $30(15.5)$ & \\
\hline University & $67(93.1)$ & $5(6.9)$ & \\
\hline
\end{tabular}




\begin{tabular}{|c|c|c|c|}
\hline \multicolumn{4}{|l|}{ Tonsillar hypertrophy } \\
\hline Not present & $148(79.6)$ & $38(20.4)$ & \\
\hline 1st grade & $113(91.1)$ & $11(8.9)$ & 0.026 \\
\hline 2nd grade & $57(81.4)$ & $13(18.6)$ & \\
\hline 3rd grade & $17(94.4)$ & $1(5.6)$ & \\
\hline \multicolumn{4}{|l|}{ Adenoids } \\
\hline Present & $100(80.6)$ & $24(19.4)$ & 0.232 \\
\hline Not present & $234(85.4)$ & $40(14.6)$ & \\
\hline \multicolumn{4}{|l|}{ Current Otitis Media } \\
\hline Normal Tympanic Membrane & 301 (89.6) & $35(10.4)$ & $<0.001$ \\
\hline Otitis media with Effusion & $33(56.9)$ & $25(43.1)$ & \\
\hline Purulent otitis media & $2(50.0)$ & $2(50.0)$ & \\
\hline \multicolumn{4}{|c|}{ Past Otitis Media or Rhinopharyngitis } \\
\hline Never had & $220(88.0)$ & $30(12.0)$ & 0.036 \\
\hline Rhinopharyngitis & $76(79.2)$ & $20(20.8)$ & \\
\hline Otitis media & $40(76.9)$ & $12(23.1)$ & \\
\hline \multicolumn{4}{|l|}{ Recurrent otitis media } \\
\hline Yes & $42(55.3)$ & $34(44.7)$ & $<0.001$ \\
\hline No & 294 (91.3) & $28(8.7)$ & \\
\hline \multicolumn{4}{|l|}{ Recurrent rhinopharyngitis } \\
\hline Yes & $22(66.7)$ & $11(33.3)$ & 0.005 \\
\hline No & $312(85.5)$ & $53(14.5)$ & \\
\hline \multicolumn{4}{|l|}{ Past antibiotic use } \\
\hline Yes & $176(74.6)$ & $60(25.4)$ & 0.008 \\
\hline No & $119(86.2)$ & $19(13.8)$ & \\
\hline \multicolumn{4}{|c|}{ *Absolute number and row percentage (in parenthesis) } \\
\hline \multicolumn{4}{|c|}{ †Hearing loss here refers to hearing loss $\geq 20 \mathrm{~dB}$ in the good ear (comprising both slight/mild and moderate-to-severe hearing loss). } \\
\hline
\end{tabular}

Table 3 presents the associations of hearing loss with the overwhelming majority of associations turn into not independent variables adjusting for multiple potential significant. confounding effects. Upon multivariable adjustment analysis

Table 3 Association of hearing impairment with socio-demographic characteristics of participants and presence of disadvantageous health conditions; multivariable adjusted analysis.

\begin{tabular}{|c|c|c|c|c|}
\hline Variable & OR * & $95 \% \mathrm{Cl}$ & $\begin{array}{l}\text { Regression } \\
\text { coefficient }\end{array}$ & p-value \\
\hline Sex & 0.6 & $0.23-1.49$ & -0.5 & 0.273 \\
\hline Parents' education & 0.83 & $0.41-1.72$ & -0.18 & 0.61 \\
\hline Place of residence & 0.43 & $0.10-1.79$ & -0.82 & 0.255 \\
\hline Tonsillar hypertrophy & 0.67 & $0.38-1.19$ & -0.39 & 0.172 \\
\hline Adenoids & 1.26 & $0.41-3.92$ & 0.23 & 0.674 \\
\hline
\end{tabular}




\begin{tabular}{|l|l|l|l|l|}
\hline Antibiotics use & 1.14 & $0.39-3.23$ & 0.12 & 0.811 \\
\hline Otitis in objective examination & 5.62 & $2.18-14.4$ & 1.72 & 0.003 \\
\hline High numb. of otitis in anamnesis & 1.82 & $1.33-2.51$ & 0.6 & 0.002 \\
\hline
\end{tabular}

The only associations preserving their statistical significance were the presence of otitis media in objective examination and the high number of past otitis media, which significantly increased the likelihood of hearing loss by 5.62 times and 1.82 times, respectively, compared to absence of current and past otitis media, respectively (Table 3 ).

\section{Discussion}

This is the first relatively large scale study to assess the prevalence of hearing loss and its association with sociodemographic factors and other health conditions affecting ear, nose and throat in preschool children in Albania. Our findings suggest the prevalence of hearing loss was relatively high $(16 \%)$ in this group of preschool children aged 4-6 years old. With regards to the etiology of hearing loss our findings suggest that it was significantly associated with the presence of current and past otitis media: children with otitis media in clinical examination and those with an anamnesis of otitis media were approximately 6 and 2 times more likely to suffer from any degree of hearing loss compared to children with no current or past otitis media, respectively.

The prevalence of any hearing loss in our study sample is very high when confronted with literature reports. This is because of the very low threshold we used in order to define hearing loss $(\geq 20 \mathrm{~dB})$. Indeed, the American SpeechLanguage-Hearing Association (ASHA) [10] uses the Clark's classification of hearing loss [11] that classifies the average hearing threshold level of $16-25 \mathrm{~dB}$ as slight hearing loss. We used such low threshold in order to be able to detect all children with a potential to develop some level of hearing loss. A study including Saudi children aged 4-8 years old reported that only $2.56 \%$ of children had a hearing impairment of $>20$ $\mathrm{dB}$ and the prevalence of hearing loss defined as $\geq 26 \mathrm{~dB}$ was $1.75 \%$ whereas among preschool children aged $4-5$ years old the prevalence of hearing loss was $2.43 \%$ [12]. However, the prevalence of moderate/severe hearing loss ( $>30 \mathrm{~dB})$ in Albania was very low $(0.5 \%)$ and lower compared to international reports [12].

The prevalence of hearing impairment $(\geq 40 \mathrm{~dB})$ among children aged 4, 5 and 6 years old was $0.093 \%, 0.107 \%$ and $0.111 \%$ in Atlanta, USA during 1991-1993 [13]. Another study among 21,427 Chinese children aged 3-6 years and who had initially passed the newborn hearing screening suggested that the prevalence of hearing impairment ( $>20 \mathrm{~dB}$ ) was $4.8 \%$ and the prevalence of permanent hearing loss (>40 dB) was $0.07 \%$ [14]. Obviously estimates of prevalence of hearing impairment across different studies are very different due to different definitions and cut-offs of hearing impairment employed, different age-ranges of children studied, extent of evaluation of hearing impairment (uni vs. bilateral), methods used to detect hearing impairment and the way rates are computed [13].

Undetected and untreated slight/mild hearing loss (>20 dB) in school-age children could pose them at greater risk of social and behavioral problems as well as poor academic performance. A study among 1528 preschool children aged 2-7 years suggested that children with mild hearing loss (20-40 dB) had significantly more phonologic, grammar and vocabulary problems compared to normal hearing children $(<20 \mathrm{~dB})$, suggesting that even mild hearing loss could be detrimental [15]. Therefore, the detection and treatment of even mild hearing impairment is important in order to prevent the adverse effects associated with it [16]. To this goal, it is suggested that the primary target population for preschool screening is children aged 4-7 years old [16].

The relationship of the prevalence of hearing impairment with gender is not straight forward. Large studies in general suggest hearing impairment to be more prevalent among male than female children with an average male to female ratio of $1.24: 1[13,17]$. In the current study we didn't find a significant difference of hearing impairment among males and females, both in univariate and multivariable adjusted analysis. Conversely, we detected a reversed trend with hearing loss being more common among females (7.2\%) than males (14.7\%), in line with some previous reports [12].

Hearing impairment in general is more common among rural children, probably due to poorer hygienic conditions and/or limited access to medical services and timely treatment $[18,19]$. Also, international literature suggests that hearing loss in children is negatively associated with parents' literacy level [2] and household income level [17]. Children whose parents have low education level are at higher risk of Chronic Otitis Media [20] which is a risk factor of hearing loss. In the current study, these associations were confirmed only in univariate analysis but when potential confounding effects were taken into consideration the associations turned not significant.

The only two factors significantly increasing the likelihood of hearing loss in preschool children in our study were presence of Otitis Media in objective examination and a history of Otitis Media. These findings are in line with international reports. Otitis Media affects almost $90 \%$ of preschool children [21] and in about $40 \%$ of cases might become a recurrent condition lasting for more than 12 months in one-tenth of affected children [22]. Otitis Media increases the risk of conductive hearing loss [23], especially in children of developing countries [24]. Otitis Media with Effusion and Chronic Otitis Media has been identified as an important etiologic factor to conductive hearing loss in preschool children in developing countries $[3,12,14,18,19,25,26]$. Whereas the contribution of Otitis Media in hearing impairment in developed countries is much lower [25] and in some studies carried out in US otitis media 
was not listed as an etiologic factor of hearing impairment [17]. However, an increase of recurrent Otitis Media prevalence among US children younger than 6 years old was reported by another study [27].

The high prevalence of hearing impairment ( $\geq 20 \mathrm{~dB}$ ) among Albanian preschool children aged 4-6 years could be attributed to several factors, including the lack of newborn screening for hearing impairment. In Albania this exercise was conducted only during 2008-2011 and then the practice was interrupted because of lack of funds, low health policy interest and priority matters. As mentioned, the newborn hearing screening is now a routine practice in developed countries [6]. Such efforts in Albania would serve to early detect the infants most at risk of hearing impairment and refer them to the appropriate services. This, in turn, would decrease the number of children diagnosed with hearing impairment later in life since a part of them would have already been detected. The current survey carried out in 2009-2011 included children aged 4-6 years old which means that they were born during 2003-2007 and thus this cohort was not affected by the newborn screening exercise occurring in 2008-2011. On the other hand, before conducting large-scale screening of newborns, the system should have in place all that it takes in order to appropriately address the test positives, in terms of definitive diagnostic procedures, correcting procedures, health staff professional skills and abilities, etc. Anecdotal evidence suggests that these elements are relatively available in Albania (mainly in the capital and major districts). Therefore, decision and policymakers need to be made aware of newborn hearing impairment screening, the current prevalence of hearing impairment among preschool children and the potential problems associated with it in order to put this issues high on health policy agenda.

Despite the high prevalence of hearing impairment evidenced in our study, most of it is due to otitis media, pointing to the conductive type of hearing loss and to the considerable correctional potential. This conclusion is based on the fact that hearing impairment was strongly and significantly associated with this health condition whereas the associations with other independent factors were not significant.

Our study has several limitations. Its cross-sectional nature does not allow drawing definitive temporal conclusions between the events. The selection bias might not be completely ruled out even though we engaged a simple random selection of individuals. Lastly, our sample is representative only of preschool children frequenting public kindergartens in Tirana. However, not all children belonging to this age-group frequent these institutions due to the lack of enough numbers of such institutions and because a good proportion of children frequents private kindergartens. Therefore, any inference to a larger population group of children would be problematic.

\section{Conclusions}

The prevalence of hearing impairment among preschool children in Tirana is considerably high. The high prevalence could be partly attributed to the lack of newborn hearing impairment screening in Albania. Policy-makers need to be aware that hearing impairment is a serious problem that negatively affects the future development of children and that routine screening of newborn and/or preschool children is an effective way to address this problem in Albania.

\section{References}

1. American Speech-Language-Hearing Association (2011) Childhood hearing loss. Audiology Information Series.

2. World Health Organization (2013) Millions of people in the world have hearing loss that can be treated or prevented.

3. Duthey B (2013) Priority medicines for europe and the world "A public health approach to innovation".

4. Olusanya BO, Neumann KJ, Saunders JE (2014) The global burden of disabling hearing impairment: a call to action. Bull World Health Organ 92: 367-373.

5. Centers for Disease Control and Prevention (CDC) (2010) Identifying infants with hearing loss - United States, 1999-2007. MMWR Morb Mortal Wkly Rep 59: 220-223.

6. Gell FM, White EM, Newell K, Mackenzie I, Smith A, et al. (1992) Practical screening priorities for hearing impairment among children in developing countries. Bull World Health Organ 70: 645-655.

7. Teele DW, Klein JO, Rosner B (1989) Epidemiology of otitis media during the first seven years of life in children in greater Boston: a prospective, cohort study. J Infect Dis 160: 83-94.

8. Nelaj E, Preza E, Bino S (2014) Vaccine coverage in Albania, 2013. Bulletin of the Institute of Public Health 3: 32-38.

9. Agjensia e Lajmeve Sot News (2013) Tirana me 40 kopshte shteterore femijesh, duhen minimalisht 230 te tille, asnje ndertim i ri ne 2 vitet e fundit.

10. (2015) Type, degree and configuration of hearing loss.

11. Clark JG (1981) Uses and abuses of hearing loss classification. ASHA 23: 493-500.

12. Al-Rowaily MA, AlFayez Al, AlJomiey MS, AlBadr AM, Abolfotouh MA (2012) Hearing impairments among Saudi preschool children. Int J Pediatr Otorhinolaryngol 76: 1674-1677.

13. Van Naarden K, Decouflé P, Caldwell K (1999) Prevalence and characteristics of children with serious hearing impairment in metropolitan Atlanta, 1991-1993. Pediatrics 103: 570-575.

14. Huang JLZ, Yang T, Li Y, Mei L, Xiang M, et al. (2011) Screening for delayed-onset hearing loss in preschool children who previously passed the newborn hearing screening. Int J Pediatr Otorhinolaryngol 75: 1045-1049.

15. Schönweiler R, Ptok M, Radü HJ (1998) A cross-sectional study of speech- and language-abilities of children with normal hearing, mild fluctuating conductive hearing loss, or moderate to profound sensoneurinal hearing loss. Int J Pediatr Otorhinolaryngol 44: 251-258. 
16. Skarznski H, Piotrowska A (2012) Screening for pre-school and school-age hearing problems: European Consensus Statement. Int J Pediatr Otorhinolaryngol 76: 120-121.

17. Mehra S, Eavey RD, Keamy DG Jr (2009) The epidemiology of hearing impairment in the United States: newborns, children, and adolescents. Otolaryngol Head Neck Surg 140: 461-472.

18. Minja BM, Machemba A (1996) Prevalence of otitis media, hearing impairment and cerumen impaction among school children in rural and urban Dar es Salaam, Tanzania. Int J Pediatr Otorhinolaryngol 37: 29-34.

19. Mann SB, Sharma SC, Gupta AK, Nagarkar AN, Dharamvir (1998) Incidence of hearing impairment among rural and urban school going children: a survey. Indian J Pediatr 65: 141-145.

20. van der Veen EL, Schilder AG, van Heerbeek $N$, Verhoeff $M$, Zielhuis GA, et al. (2006) Predictors of chronic suppurative otitis media in children. Arch Otolaryngol Head Neck Surg 132: 1115-1118.

21. Paradise JL, Rockette HE, Colborn DK, Bernard BS, Smith CG, et al. (1997) Otitis media in 2253 Pittsburgh-area infants: prevalence and risk factors during the first two years of life. Pediatrics 99: 318-333.
22. Williamson IG, Dunleavy J, Baine J, Robinson D (1994) The natural history of otitis media with effusion - a three-year study of the incidence and prevalence of abnormal tympanograms in four South West Hampshire infant and first schools. J Laryngol Otol 108: 930-934.

23. Joint Committee on Infant Hearing (2000) Year 2000 position statement: principles and guidelines for early hearing detection and intervention program. Paediatrics 106: 798-817.

24. World Health Organization (2004) Chronic Suppurative Otitis Media: Burden of Illness and Management Options.

25. Monasta L, Ronfani L, Marchetti F, Montico M, Brumatti LV, et al. (2012) Burden of disease caused by otitis media: systematic review and global estimates. PLoS One 7: e36226.

26. Adebola SO, Ayodele SO, Oyelakin OA, Babarinde JA, Adebola OE (2013) Pre-school hearing screening: profile of children from Ogbomoso, Nigeria. Int J Pediatr Otorhinolaryngol 77: 1987-1991.

27. Lanphear BP, Byrd RS, Auinger P, Hall CB (1997) Increasing prevalence of recurrent otitis media among children in the United States. Pediatrics 99: E1. 